\title{
The Influence of Structured Information and Monitoring on the Outcome of Asthma Treatment in Primary Care: A Cluster Randomized Study
}

\author{
Mika Nokela ${ }^{a, b}$ Marianne Heibert Arnlind ${ }^{a, d}$ Per-Olof Ehrs ${ }^{a, c}$ Ingvar Krakau ${ }^{a, e}$ \\ Lennart Forslund $^{f}$ Eva Wikström Jonsson ${ }^{a, b}$ \\ a Department of Medicine Solna, Karolinska Institutet, Clinical Pharmacology Unit L7:05, Karolinska University \\ Hospital, ${ }^{b}$ Centre for Allergy Research, ' Lung and Allergy Research, Division of Physiology, \\ National Institute of Environmental Medicine, ${ }^{d}$ Medical Management Centre, Department of Learning, Informatics, \\ Management and Ethics, and ${ }^{\mathrm{D}}$ Department of Medicine Solna, Karolinska Institutet, and \\ ${ }^{f}$ Medical Products Agency, Stockholm, Sweden
}

\section{Key Words}

Asthma - Asthma control $\cdot$ Information - Primary care • Quality of life

\begin{abstract}
Background: In clinical trials of asthma, the outcomes are often good, but when the same treatment regimens are implemented in primary care, equally good results are not obtained. Objective: To investigate if addition of structured patient information and monitoring by an asthma diary in primary care improves asthma control. Methods: $141 \mathrm{pa}-$ tients from 19 primary care centres were studied. The centres were randomised to a standard care group or to an intervention group. The intervention group received structured written and oral information about asthma and asthma medication, and were instructed to keep an asthma diary. The primary outcome was asthma control as assessed by the Asthma Control Questionnaire. Secondary outcomes were costs of asthma medication, the Mini Asthma Quality of Life Questionnaire score and lung function. Results: Asthma Control Questionnaire score changes differed between the
\end{abstract}

study groups $(p<0.05)$. In the intervention group, these changes $(M=-0.45)$ in asthma control were close to clinical significance (minimal important difference $\approx 0.5$ ). Both groups improved in disease-specific quality of life scores. For the intervention group, which changed the most $(p<0.05)$, the change exceeded the threshold for the minimal important difference (0.5). The costs of medications increased significantly in the intervention group, where adjustments of medication were made more often than in controls. Conclusion: Disease-specific quality of life of asthma patients could be improved by adding structured information and monitoring by diary to standard care. Copyright $\odot 2009$ S. Karger AG, Basel

\section{Introduction}

Asthma is a chronic disease with a prevalence of about 8\% in the European population [1]. Although effective symptomatic treatment is available, under-diagnosis and poor management is a problem $[2,3]$. International guidelines emphasize that written action plans and patient ed-

\section{KARGER}

Fax +41613061234 E-Mail karger@karger.ch www.karger.com (c) 2009 S. Karger AG, Basel

0025-7931/10/0795-0388\$26.00/0

Accessible online at:

www.karger.com/res
Mika Nokela

Department of Medicine Solna, Karolinska Institutet

Clinical Pharmacology Unit L7:05, Karolinska University Hospital, Solna

SE-171 76 Stockholm (Sweden)

Tel. +46 7339499 18, Fax +4683313 43, E-Mail mika.nokela@ki.se 
ucation, in addition to regular follow-up, are important in order to achieve successful self management [4]. Nevertheless, adherence to asthma treatment guidelines is generally poor [5-7] and guideline goals are not achieved [1]. This is probably due to non-adherence to guidelines as well as to insufficient patient co-operation. It has been suggested that only half of patients with chronic diseases take their medicines as prescribed $[8,9]$. Compliance and treatment outcome are better in clinical trials than in everyday care [10]. Several components in the trial situation could account for this. One of them is the increased information given to participants in clinical trials. That this could be an important factor is supported by the health beliefs model [11]. Another trial component of probable importance is the more extensive follow-up and monitoring of treatment effects in trials compared to ordinary care.

The poor outcomes of asthma treatment in everyday care, due to suboptimal treatment regimens and lack of patient adherence, probably inflate the costs of asthma [12]. Asthma-related costs are determined largely by pharmaceuticals [13] and vary considerably even among patients with similar asthma severity [14].

Our aim was to evaluate if an intervention containing 2 of the crucial elements of clinical trials, active monitoring and increased information, might improve the treatment outcome in asthmatic patients in primary care. The intervention consisted of structured written and oral information, and an asthma diary. The primary outcome measure was asthma control. Secondary outcomes were estimates of costs of asthma medication, asthma-specific quality of life and pulmonary function.

\section{Material and Methods}

From October 2003 until December 2004, we studied 141 participants (98 females and 43 males), aged 18-87 years, who were treated in 19 primary healthcare centres in the Stockholm area. The centres were instructed to consecutively invite all eligible patients with an asthma diagnosis who sought medical attention (for any condition) to participate. All participants had to give written informed consent. Exclusion criteria were: age less than 18 years, poor understanding of written Swedish, malignant disease, severe psychiatric disease and dementia. All participants gave written informed consent to their participation.

The study was designed to measure the effect of increased information and monitoring by diary on treatment outcome in asthmatic patients in primary care. Study centres were randomized to a control group, treating asthmatic patients according to their local routines, or to an intervention group (see below). Randomization of the centres was performed by an independent consultant, Dr. Pierre Lafolie at the Karolinska Trial Alliance, Stock- holm, Sweden, after inclusion of all centres but before patient recruitment started. Randomization was performed using a computer programme that generated random numbers. Both the patients and the researchers analyzing the data were aware of the allocation.

The intervention was delivered by the treating physician or an asthma nurse, depending on local routines, and consisted of giving additional structured written and oral information, and follow-up using an asthma diary. Basic information aetiology, pathology and management of asthma (1 page) was given to all patients in the intervention group. Information on specific asthma treatment was standardized for different medications, but individualized for each patient so that only information applicable to his/her current treatment was given (less than 1 page per class of medication). The same information was also given orally. Participants in the intervention group were also instructed to keep an asthma diary and to discuss the diary with the appointed nurse. The diary consisted of a pre-printed booklet with 4 questions that were to be answered on a daily basis, preferably before the first daily dose of medicine. The questions concerned use of bronchodilators on demand, nighttime awakenings due to asthma, and treatment adherence. It was estimated that the intervention, diary excluded, would take approximately $10 \mathrm{~min}$ to carry out.

The primary outcome measure was the change in the score of the asthma control questionnaire (ACQ) between the 2 visits in the study. We used the Swedish 5-question version of the ACQ, which has been validated for use in a primary care setting [15-17]. Each item is scored on a 7-point scale $(0=\operatorname{good}$ control, $6=$ bad control), and the overall score is the mean of all responses. The minimal important difference (MID) has been reported to be close to \pm 0.5 [16]. Two different approaches to calculating the MID showed similar, but not identical results, thus creating slight uncertainty [16].

Secondary outcomes were lung function measurements $\left(\mathrm{FEV}_{1}\right.$ or PEF), the number of self-reported emergency visits caused by asthma, the number of patients having additional/unanswered questions about their asthma or its management, prescribed changes in drug treatment, the patient-perceived benefit of asthma medications, costs of the asthma medications, and changes in disease-specific quality of life. Disease-specific quality of life was measured using the validated Swedish version of the Mini Asthma Quality of Life Questionnaire (MiniAQLQ; MID 0.5), which yields a total score between 1 and 7 , where 7 is the best and 1 is very poor $[17,18]$.

The participants completed 2 visits $8-14$ weeks apart at their primary health care centre. At the first visit, they were characterized with regard to age, gender, asthma symptoms and asthma medications used during the preceding week. Lung function was measured with ongoing medication by spirometry or a peak-flow meter according to local routines. A standardized approach with spirometry for all participants would have required a change to normal clinical routines, which was undesirable. The participants completed the ACQ [15] and the MiniAQLQ [18]. Designated nurses were responsible for the handling of the questionnaires. At the second visit, both questionnaires were completed again and spirometry or PEF was carried out in the same way as at the first visit. Each patient also completed a questionnaire that addressed the number of emergency department visits caused by asthma since the last visit, additional questions about their treatment (yes/no), if prescribed drug treatment had been changed (yes/no), 
if the patient perceived benefit of the treatment (yes/no), and asthma medications taken during the preceding week.

The daily doses of each asthma drug were used to calculate the total daily pharmaceutical costs per patient. If the dosage of a drug was not recorded, we used the cost of a defined daily dose of the drug [19]. Unit costs for drugs were obtained from the Swedish pharmaceutical desk reference, FASS ${ }^{\circledR}, 2004$ [20]. For comparison of costs, 1 USD = 7. 47 SEK (2005) [21].

The study was approved by the regional ethical review board.

\section{Statistical Analysis}

The study was designed as a prospective, cluster-randomized trial. Thus, study centres rather than patients were randomized to control or intervention in order to avoid contamination between subjects. However, this design does not allow assumptions of independence between patients within the same centre (cluster). This is taken into account by comparing the means of all observations for all subjects within a cluster between treatment groups, weighting for cluster size [22].

Power calculations were carried out to obtain a power of 0.8 with $\alpha=0.05$ on an individual level to detect a difference in ACQ score at least as large as the MID (0.5 p). The resulting required sample size was 67 in each group. To evaluate the extent to which the design affected the power of our study, we used a measure known as 'the design effect' [23]. It is calculated according to the formula:

Design effect $=1+(m-1) \times$ ICC

where $\mathrm{m}$ is the average cluster size and ICC is the intra-class correlation coefficient [24]. For example, if the design effect is 4 , then a cluster trial will require 4 times the number of individuals required by a simple randomized trial of individuals. An estimate of the ICC can be obtained by using mean square (MS) values from a 1-way analysis of variance:

$$
\mathrm{ICC}=\left[\mathrm{MS}_{\text {between }}-\mathrm{MS}_{\text {within }} / \mathrm{MS}_{\text {between }}+(\mathrm{m}-1) \mathrm{MS}_{\text {within }}\right]
$$

where MS values are the mean squares from the ANOVA table and $\mathrm{m}$ is the average size of the clusters [25]. This method is equally applicable for both binary and continuous outcomes [25]. The size of each cluster in our study varied. Therefore, we substituted m0 for $\mathrm{m}$ :

$$
\mathrm{m} 0=1 /(\mathrm{k}-1)\left[\mathrm{n}-\left(\sum \mathrm{m}_{\mathrm{i}}^{2} / \mathrm{n}\right)\right]
$$

where $\mathrm{k}$ is the total number of clusters, $\mathrm{m}_{\mathrm{i}}$ is the number of cases in the ' $\mathrm{i}$-th' cluster, with i ranging from 1 to $\mathrm{k}$, and $\mathrm{n}$ is the total number of individuals in the sample in our calculation [25].

The effect of the intervention was described by the change within subjects after the intervention and compared between groups with weighted t tests. The Pearson $\chi^{2}$ was used to analyse the variables in the short questionnaire (change in drug treatment, patient perceived benefit, number of emergency visits, and additional questions). To account for the clustering effect in the analysis, adjusted $\chi^{2}$ values were calculated by dividing the $\chi^{2}$ statistic with the design effect for the variable in question $[26,27]$.

Mean values and standard deviations are given, unless otherwise specified. For all statistical tests, $\mathrm{p}<0.05$ was considered statistically significant. All descriptive analyses and t tests were carried out using Systat 11 (Systat Software, Richmond, Calif., USA). $\chi^{2}$ and adjusted $\chi^{2}$ analyses were calculated manually.

\begin{tabular}{|c|c|c|}
\hline & $\begin{array}{l}\text { Intervention } \\
\text { group }\end{array}$ & $\begin{array}{l}\text { Control } \\
\text { group }\end{array}$ \\
\hline Male/female & $n=64$ & $n=77$ \\
\hline $\mathrm{n}$ & $16 / 48$ & $27 / 50$ \\
\hline$\%$ & $25 / 75$ & $35 / 65$ \\
\hline Age, years $(\min -\max )$ & $48(19-87)$ & $52.5(18-79)$ \\
\hline \multicolumn{3}{|l|}{ Smoking habit, $\mathrm{n}(\%)$} \\
\hline Smokers & $9(14)$ & $14(18)$ \\
\hline Ex-smokers & $29(45)$ & $31(40.3)$ \\
\hline Non-smokers & $26(41)$ & $31(40.3)$ \\
\hline Missing data & 0 & $1(1.3)$ \\
\hline \multicolumn{3}{|l|}{ Asthma control } \\
\hline ACQ & 1.51 & 1.52 \\
\hline \multicolumn{3}{|c|}{ Disease-specific quality of life } \\
\hline MiniAQLQ & 5.22 & 5.02 \\
\hline \multicolumn{3}{|l|}{ Lung function } \\
\hline $\mathrm{FEV}_{1}, \%$ of predicted & $n=64$ & $n=64$ \\
\hline Mean & 89 & 82.6 \\
\hline Min-max & $33-127$ & $5-118$ \\
\hline PEF & $n=16$ & $n=27$ \\
\hline Mean & 350 & 295 \\
\hline Min-max & $88-600$ & $45-650$ \\
\hline \multicolumn{3}{|c|}{ Records on PEF or $\mathrm{FEV}_{1}, \mathrm{n}(\%)$} \\
\hline Total & $64(100)$ & $70(91)$ \\
\hline Missing & 0 & 7 \\
\hline \multicolumn{3}{|c|}{ Total daily cost of drugs per patient (visit 1), SEK } \\
\hline Mean & 8.14 & 12.60 \\
\hline Median & 7.92 & 11.48 \\
\hline Min-max & $0-25.77$ & $0-40.40$ \\
\hline
\end{tabular}

Table 1. Patient characteristics $(n=141)$

\section{Results}

The enrolment lasted 14 months and was conducted in parallel for the 2 groups. The seasonal impact on asthma symptoms and severity can thus be assumed to be equal in the treatment groups. 168 participants were enrolled; 11 participants in the control group and 10 in the intervention group were lost to follow-up for unknown reasons. One patient in the intervention group did not meet the age inclusion criteria and was therefore excluded. Three controls and 2 participants in the intervention group completed the second visit much later than planned in the protocol (20-32 weeks overdue) and were therefore excluded. Thus, 64 participants in the intervention group and 77 in the control group completed the study. Post hoc calculations revealed that the design effect for the primary outcome, ACQ, was 1.20 , which implies that the sample should have been inflated by $20 \%$ to reach the desired power of 0.8 . 
Table 2. The intracluster correlation coefficient and test statistics with $\mathrm{p}$ values for all analysed variables

\begin{tabular}{|c|c|c|c|c|}
\hline Variable & $\begin{array}{l}\text { Intracluster } \\
\text { correlation } \\
\text { coefficient }\end{array}$ & $\begin{array}{l}\mathrm{t} \\
\text { value }^{\mathrm{a}}\end{array}$ & $\begin{array}{l}\text { Adjusted } \\
\chi^{2} \\
\text { statistic }^{b}\end{array}$ & $\begin{array}{l}\mathrm{p} \\
\text { value }\end{array}$ \\
\hline ACQ, change in score & 0.03 & 3.51 & & 0.01 \\
\hline \multicolumn{5}{|l|}{ Lung function, change in } \\
\hline $\mathrm{FEV}_{1}, \%$ predicted & 0.03 & -2.45 & & 0.02 \\
\hline Costs, mean change & 0.10 & -3.04 & & 0.00 \\
\hline \multicolumn{5}{|l|}{ MiniAQLQ, change } \\
\hline in scores & 0.004 & -5.72 & & $<0.001$ \\
\hline \multicolumn{5}{|l|}{ Number of acute emergency } \\
\hline department visits & 0.06 & & 0.61 & 0.43 \\
\hline \multicolumn{5}{|l|}{ Patient perception of drug } \\
\hline benefit & 0.002 & & 2.2 & 0.14 \\
\hline \multicolumn{5}{|l|}{ Prescribed change in drug } \\
\hline treatment & 0.29 & & 3.96 & 0.05 \\
\hline Having additional questions & 0.04 & & 0.28 & 0.6 \\
\hline
\end{tabular}

The demographic characteristics of the patients included in the final analysis of the study are presented in table 1 . The dropouts did not differ from the other participants at baseline (not shown).

The changes in ACQ scores differed significantly, $\mathrm{t}(137)=3.51, \mathrm{p}=0.01$ between the control group $(\mathrm{M}=$ $-0.29, \mathrm{SD}=0.31)$ and the intervention group $(\mathrm{M}=-0.45$, $\mathrm{SD}=0.23$ ). However, the difference in mean change was less than the MID $\approx \pm 0.5$ in the control group. The changes in lung function also differed significantly $\mathrm{t}(137)=-2.45, \mathrm{p}=0.016$ between, the control group $(\mathrm{M}=1.39, \mathrm{SD}=3.53)$ and the intervention group $(\mathrm{M}=$ $3.03, \mathrm{SD}=4.34)$.

In the control group, there were 7 emergency visits by 6 participants, and in the intervention group, there were 9 emergency visits by 5 participants (cluster-adjusted $\left.\chi^{2}=0.61, \mathrm{p}=0.43\right)$.

There was no difference between the 2 groups regarding the perception of drug benefit (cluster-adjusted $\chi^{2}=$ $2.17, \mathrm{p}=0.14)$. However, the proportion of participants who altered their pharmaceutical treatment was significantly larger in the intervention group than in the control group (cluster-adjusted $\chi^{2}=3.96, p=0.0466$ ). The number of participants having additional questions at followup was 10 participants per group.

Influence of Structured Information and Monitoring on Asthma Outcome
Both groups improved their disease-specific quality of life during the study (change scores in the positive direction). The magnitude of change was $\mathrm{M}=0.28, \mathrm{SD}=0.31$, in the control group and $\mathrm{M}=0.53, \mathrm{SD}=0.18$ in the intervention group $[t(137)=-5.72, p<0.05$ for the group difference]. The magnitude of change exceeded the threshold for the MID (0.5) in the intervention group.

Weighted total mean costs were SEK 8.14 for the intervention group and SEK 12.59 for the control group at baseline. At follow-up, the total cost had increased by SEK 1.50/day in the intervention group, whilst it remained almost the same in the control group (a decrease ofSEK 0.12/day). The weighted difference between groups was statistically significant $[\mathrm{t}(139)=-3.04, \mathrm{p}<0.05]$. The increased costs could not be attributed to any single class of medications.

The mean total cost per centre/day varied from SEK 2.79 to 17.40 for the intervention centres and from SEK 6.37 to 16.90 for the control centres at baseline. At followup, the mean total cost per centre varied from SEK 4.62 to 17.40 for the intervention centres and from SEK 8.02 to 23.05 for the control centres.

The intracluster correlation coefficients for outcomes reported above are presented in table 2.

\section{Discussion}

Our findings suggest that structured information and monitoring has a positive effect on the outcome of asthma treatment in the primary care setting. Thus, asthma control improved and there was a clinically significant improvement in asthma-specific quality of life among patients cared for at primary care centers randomized to the intervention group compared to usual care. This is in line with previous findings in self-management programs [28]. The cost of medication in the intervention group increased by SEK 1.50/day, due to changes in patient-reported medication. The baseline gap between the groups regarding costs was slightly reduced, but they still differed, with the intervention group having the lowest total costs.

Changes in the primary outcome measure, asthma control measured by the ACQ, were small and did not exceed the threshold for the MID. A small, but statistically significant improvement of lung function was also detected in the intervention group. The clinical relevance of these changes is thus uncertain. However, only shortterm effects were evaluated in the present study. It would be interesting to study whether there are long-term ben-

Respiration 2010;79:388-394 
Fig. 1. Flow diagram of the progress of

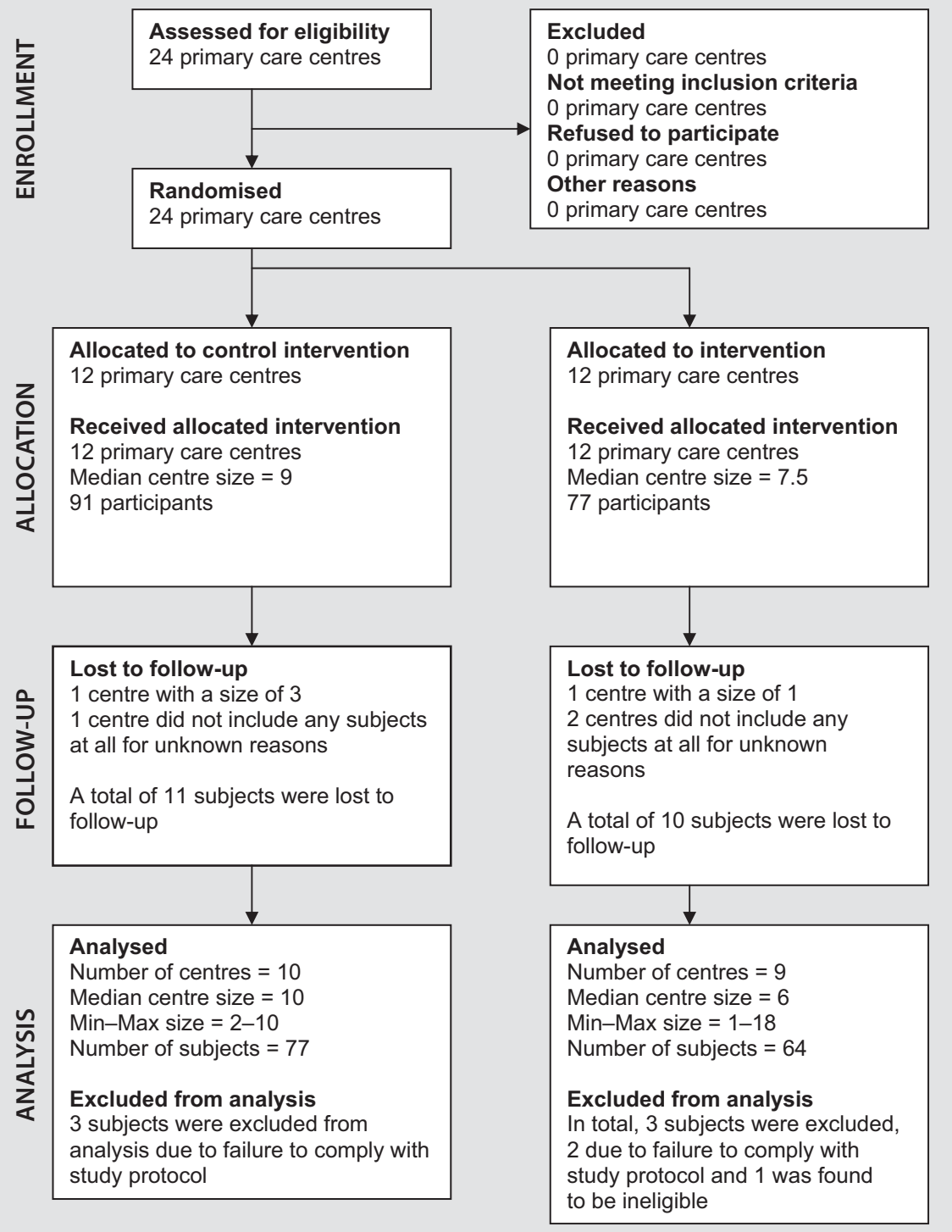
clusters and individuals through the trial.

efits, but that would have required a longer study, possibly repeating the intervention ('a booster dose').

The finding that prescribed medical changes were greater in the intervention group is interesting. The delivery of structured information might have initiated more discussions about the current treatment, resulting in changes of treatment. Even though the intervention group had more changes in prescribed medications and significantly increased pharmaceutical costs, the mean cost was still lower in the intervention group than in the control group due to an imbalance at baseline. The large range of pharmaceutical costs per day and patient are in line with previous findings [14].
Considering the limitations of our study, it is possible that the clinicians made selective invitations which could bias the results. This would, however, be against their instructions, and we have no reason to believe that this was the case. We had problems with a relatively high rate of loss to follow-up; however, these patients did not differ from the ones in the final analysis at baseline. This, and the post hoc analysis of the cluster effect, led to a lower statistical power than anticipated. Nonetheless, positive effects of the intervention could be documented. Furthermore, we chose a self-reported primary outcome. The validity of self-reported measures could be questioned, but they are considered important and their use is advo- 
cated in current guidelines for asthma treatment. In this case, the primary outcome measure, ACQ in its original design, consisted of 2 'objective' items (short-acting b2agonist use and $\mathrm{FEV}_{1}$ ), which were later excluded due to redundancy [16]. Researchers and study subjects were not blinded. However, contamination was minimized by presenting the intervention merely as an approach different from standard care and not giving details on its content to centres allocated to the standard care group.

The robustness of the primary outcome and our efforts to minimise bias and contamination between the study groups makes us confident that confounding is not a major threat to our conclusion.

The fact that the study was underpowered is of less importance. Underpowering a study is a major threat to the validity of the findings only if no statistically significant differences are found in the outcomes.

\section{Conclusion}

Our intervention, structured information given only once and monitoring at home by an asthma diary, had small but significant effects on asthma-specific quality of life. Nevertheless, the effects seen in our study are com- parable to those seen in large patient-education programs on self-management, that include self-monitoring by either PEF or symptoms, coupled with regular medical review and a written action plan [29]. This suggests that giving more and relevant information within the everyday asthma-consultation and actively monitoring may improve treatment outcome with only a minor increase in effort.

\section{Practice Implications}

Large patient education programs have been viewed as expensive, carrying high start-up costs [30]. However, structured information to patients in connection with regular visits and monitoring with an asthma diary require little additional resources and are easy to accomplish.

\section{Acknowledgments}

We thank all participants, the staff in the primary care centres, and research nurse Lena Wahlberg. We also thank Prof. Paul Hjemdahl for valuable comments on the manuscript. The study was supported and funded by the drug and therapeutics committees in Stockholm and Sörmland, the Stockholm County Council, the Vårdal Foundation and the Karolinska Institutet.

\section{References}

1 Rabe KF, Vermeire PA, Soriano JB, Maier WC: Clinical management of asthma in 1999: the Asthma Insights and Reality in Europe (AIRE) study. Eur Respir J 2000;16: 802-807.

$\checkmark 2$ Vermeire PA, Rabe KF, Soriano JB, Maier WC: Asthma control and differences in management practices across seven European countries. Respir Med 2002;96:142-149.

-3 Hasselgren M, Arne M, Lindahl A, Janson S, Lundback B: Estimated prevalences of respiratory symptoms, asthma and chronic obstructive pulmonary disease related to detection rate in primary health care. Scand J Prim Health Care 2001;19:54-57.

4 Global Initiative for Asthma: Global strategy for asthma management and prevention. National Institutes of Health, National Heart, Lung and Blood Institute, 2002.

5 de Vries TW, Tobi H, Schirm E, van den Berg P, Duiverman EJ, de Jong-van den Berg LT: The gap between evidence-based medicine and daily practice in the management of paediatric asthma: a pharmacy-based population study from The Netherlands. Eur J Clin Pharmacol 2006;62:51-55.
6 Hoskins G, McCowan C, Donnan PT, Friend JA, Osman LM: Results of a national asthma campaign survey of primary care in Scotland. Int J Qual Health Care 2005; 17:209215.

7 Janson C, Chinn S, Jarvis D, Burney P: Physician-diagnosed asthma and drug utilization in the European Community Respiratory Health Survey. Eur Respir J 1997;10:17951802 .

-8 Cochrane GM, Horne R, Chanez P: Compliance in asthma. Respir Med 1999;93:763769.

-9 van Staa TP, Cooper C, Leufkens HG, Lammers JW, Suissa S: The use of inhaled corticosteroids in the United Kingdom and the Netherlands. Respir Med 2003;97:578-585.

$\checkmark 10$ Jonasson G, Carlsen KH, Mowinckel P: Asthma drug adherence in a long term clinical trial. Arch Dis Child 2000;83:330-333. 11 Janz NK, Becker MH: The Health Belief
Model: a decade later. Health Educ Q 1984; 11:1-47.

12 Barnes PJ, Jonsson B, Klim JB: The costs of asthma. Eur Respir J 1996;9:636-642.
13 Cisternas MG, Blanc PD, Yen IH, Katz PP, Earnest G, Eisner MD, Shiboski S, Yelin EH: A comprehensive study of the direct and indirect costs of adult asthma. J Allergy Clin Immunol 2003;111:1212-1218.

14 Arnlind MH, Nokela M, Rehnberg C, Jonsson EW: The relationship between pharmaceutical costs, disease severity, and health-related quality of life in asthmatics in Swedish primary care. J Asthma 2006;43: 585-591.

15 Juniper EF, O’Byrne PM, Guyatt GH, Ferrie PJ, King DR: Development and validation of a questionnaire to measure asthma control. Eur Respir J 1999;14:902-907.

16 Juniper EF, Svensson K, Mork AC, Stahl E: Measurement properties and interpretation of three shortened versions of the asthma control questionnaire. Respir Med 2005;99: 553-558.

17 Ehrs PO, Nokela M, Stallberg B, Hjemdahl P, Wikstrom Jonsson E: Brief questionnaires for patient-reported outcomes in asthma: validation and usefulness in a primary care setting. Chest 2006;129:925-932. 
18 Juniper EF, Guyatt GH, Cox FM, Ferrie PJ, King DR: Development and validation of the Mini Asthma Quality of Life Questionnaire. Eur Respir J 1999;14:32-38.

19 Guidelines for ATC classification and DDD assignment. Nydalen, World Health Organization Collaborating Centre for Drug Statistics, 1996.

20 FASS (Pharmaceutical specialities in Sweden, equivalent to PDR). Stockholm, Swedish Association of the Pharmaceutical Industry (LIF), 2003.

21 Exchange rates, annual aggregate. www. riksbank.com/templates/stat.aspx?id=17211 (accessed June 22, 2009).
22 Kerry SM, Bland JM: Analysis of a trial randomised in clusters. BMJ 1998;316:54.

23 Kerry SM, Bland JM: Sample size in cluster randomisation. BMJ 1998;316:549.

24 Kerry SM, Bland JM: The intracluster correlation coefficient in cluster randomisation. BMJ 1998;316:1455.

25 Parker DR, Evangelou E, Eaton CB: Intraclass correlation coefficients for cluster randomized trials in primary care: the cholesterol education and research trial (CEART). Contemp Clin Trials 2005;26:260-267.

-26 Reed JF 3rd: Adjusted chi-square statistics: application to clustered binary data in primary care. Ann Fam Med 2004;2:201-203.

27 Colton T, Redmond CK: Biostatistics in clinical trials. Chichester, John Wiley \& Sons, 2001.
28 Warsi A, Wang PS, LaValley MP, Avorn J, Solomon DH: Self-management education programs in chronic disease: a systematic review and methodological critique of the literature. Arch Intern Med 2004;164:16411649.

29 Gibson PG, Powell H, Coughlan J, Wilson AJ, Abramson M, Haywood P, Bauman A, Hensley MJ, Walters EH: Self-management education and regular practitioner review for adults with asthma. Cochrane Database Syst Rev 2003:CD001117.

30 Cabana MD, Le TT: Challenges in asthma patient education. J Allergy Clin Immunol 2005;115:1225-1227. 